\title{
Comparing the Adopters and Non-Adopters of Online Social Networks: A UK perspective.
}

\begin{abstract}
This paper aims to identify, explain and understand the adoption, use and diffusion of OSNs within UK's older population. This was achieved using a quantitative online survey questionnaire. Results from a sample population of 252 participants' revealed that age, gender, education, Internet usage history and usage frequencies are all associated with adoption rates. However, it was also learnt that Internet speed is not associated with adoption and is a factor that requires further investigations. Contributions for academia include application of an empirically tested Model of OSN Adoption (MOSN) that employed previous IS theories; DIT, MATH \& DTPB. For policymakers our research recommends that age should be considered when developing and implementing novel and innovative technologies. For industry our study identifies specific factors of consideration for wider penetration of OSNs in UK's population.
\end{abstract}

Keywords: Online Social Networks, Usage, Diffusion, Adoption, Demographics, UK. 


\section{Introduction}

As novel technologies such as Broadband have emerged and become part of daily life, Internet usage has grown and affected the global behavior of Internet users [1]. Such innovations have led to the development of innovative communication platforms such as, Electronic (e)-mail and Instant Messaging (IM). This ability to use the Internet and associated technologies not only for information seeking, but also communication, has changed the presence of the Internet in peoples' lives. Transformations have occurred in the way that the Internet is used. From a medium for the elite, Internet use has become essential for daily life $[2,3]$. ICTs are an array of primarily digital technologies designed to collect, organise, store, process and communicate information [4]. Widely used ICTs include broadband, email and instant messaging. Additionally due to wider adoption and use ICTs are being promoted for economic growth and poverty reducing strategies [5].

These developments have also led to the inception of online user communities, which can contribute significantly to the success of an on-line platform [6]. Such success has paved the way for a second generation of 'opensource, interactive and user controlled online applications', known as Web 2.0 Online Social Networks (OSNs) [7]. OSNs such as Facebook, Linkedin and Twitter are "applications allowing users to build personal websites accessible to other users for exchange of personal content and communication" [8] The concept of OSNs is described as, "when a computer network connects people, it is a social network. Just as a network is a set of machines connected by a set of cables, a social network is a set of people (or organizations or other social entities) connected by a set of socially meaningful relationships" [9]. The growth and popularity of OSNs has propagated a new world of collaboration and communication [10]. A current example of OSN adoption and growth is the widely known OSN Facebook, which has within 6 years of launch an estimated $8 \%$ of the world's population subscribed as members. These numbers amount to 845 million active users and 75 languages across the world [11]. LinkedIn a leading professional OSN currently hosts over 100 million users [12]. Twitter a micro blogging orientated OSN host's 106 million users [13]. It can be seen that based on these three leading OSNs over 1 billion global individuals have adopted and become regular users of OSNs.
Globally, OSN websites are considered to be the most popular online category when ranked by average time spent per Internet user [14]. In Europe, United Kingdom (UK) has seen the largest numbers of OSN adopters and users [15]. For a growing number of Internet users, maintaining an OSN profile page has become a part of their daily activities [16]. Professional use of OSNs as an easy and efficient way to build and maintain offline social networks in an online manner is also emerging in business practice management [17]. Further, governments are also viewing OSNs as an important channel to maintain interaction between online government agencies and citizens; therefore, efforts to leverage web 2.0 initiatives for citizen-to-government interaction are also being made [18]. However, although OSN popularity is assumed to be diverse and widespread, this is not apparent when analysing the age split of UK OSN users. Statistics reveal that younger adults (50 years and below) hold the majority of users while older adults $(50+$ years) remain the minority adopters of leading OSNs such as Facebook, MySpace and Twitter [19].

Information Systems (IS) research has attempted to explore this issue by identifying younger ICT individuals as 'digital natives' [20]. These are individuals born after the 1980s when social digital technologies were implemented online and have from their early years in life had access to digital networked technologies such as OSNs; therefore they have the skills and abilities to learn how to use them [21]. For these reasons, within this paper, younger adults will be used as a baseline to compare the OSN behavior of older adults.

A note to readers, older adults are defined as internet users 50 years old or above and are also referred to as 'silver surfers' [22]. Whilst penetration and adoption rates of OSNs reveal differences, research of older users is pertinent for the following reasons: (1) Little is still known about the reasons and motivations underlying older adults' adoption or nonadoption of ICTs such as OSNs [23], yet the world's population is viewed to be rapidly ageing with over 60 s set to rise to $22 \%$ in 2050 [24]. The UK is also anticipated to have an ageing population, which is anticipated sooner than 2050 [25]: 'More than one third of the UK's population will be over 55 by 2025' [26]. (2) Digital technologies can facilitate everyday tasks; thereby enabling disadvantaged demographic groups' users, such as, older adults to remain independent longer. By doing so, information such as, advanced and updated medical advances and technologies information 
can be obtained and implemented such that their quality of life can be increased [27].

As the reasons for examining this group of society are critical and gaps in research examining the acceptance of OSNs amongst the older population was scarce, this research team was motivated to conduct research with the aim: To identify, explain and understand the adoption, use and diffusion of OSNs within the UK population.

The contributions of this research to academia is viewed to be the development of an understanding of whether Facebook, a popular OSN that is leading to investments from governments such as, the UK is leading to adopters and non-adopters, in groups of society such as, the disadvantaged groups of older adults, lower income groups or the disabled. For industry, Internet Service Providers, OSN providers can determine whether their developed and implemented policies and strategies will lead to success by referring to a research study as this. Policy makers can use research findings to assist developments in internet based government-to-citizen communication and drive digital inclusion for older adults, in efforts to reduce the digital divide in the UK.

To inform readers a structure of this paper is provided: First an introduction and overview of the research issue is provided leading to research aims. The following section provides a review of OSN and digital divide: young \& old literature. The preceding two sections present the theoretical background and development of the proposed theoretical conceptual framework. The research methodology is then described. Analysis and model testing with findings of this research pertaining to OSN adoption, OSN diffusion and OSN diffusion for both older and younger individuals is then presented and comparatively explained, followed with discussion. The final section provides conclusions, implications, limitations and future directions.

\section{Literature Review}

\subsection{Online Social Networks}

When Facebook and MySpace were generally examined, gender and personality were revealed to be predictors of OSN behavior. Further, gender and personality were related to both participants' reasons for using OSNs and their usage and participation in OSN socializing [28]. When comparing and contrasting real world social networks with those of OSNs, a reason for adopting a new technology is strongly influenced by the actions of the connected others within the online social group [29]. Very closely related to the theoretical foundations and aims of this research previous research [30] utilized MATH theory to comparatively analyze internet adoption within three different age groups (39 and below, 40-59 and 60+). Results proved that MATH is of great value when predicting usage intention among all age groups, especially among the elderly (60 years and older). Other research [31] also examined the adopters and non-adopters of OSNs using MATH [32] and found the model being suitable for examining elderly people. Further, hedonic outcomes (fun) bearing no impact on OSN use intention [33]. Currently information uploaded to Facebook may be traded for commercial value, but if there was a fee imposed to users to protect their personal information, [34] found that $48.1 \%$ of participants are not willing to pay a single euro; therefore, valuing their personal information at zero.

\subsection{The Digital Divide: Young \& Old}

Differences between users can be associated with the digital divide that has been conceptualized as operating on three levels [35]. This research subscribes to the third level: 1) The global divide refers to the divergence of internet access between industrialized and developing countries; 2) The social divide concerns the gap between information rich and information poor in each nation; 3) The democratic divide signifies the difference between those who do, and those who do not, use the panoply of digital resources to engage, mobilise, and participate in public life. A basic strategy for overcoming the digital divide has been to provide physical access to computers; but, as [36] clarifies, there are additionally three further aspects with regard to resources: Digital resources (material made available online); Human resources (in particular literacy and education) and Social resources (the community, institutional and societal structures that support access to IT). The aspects that [37] identified as important also formed the basis of this research when considering the adoption and usage of OSNs within older individuals. Younger adults use of OSNs has also been investigated [38] where results showed that Facebook was routinely used, on average, for 30 minutes a day, primarily for social interaction with offline established friends. Although generally, [39] determined relationship quality, individual's support through OSNs, suggest that Facebook is facilitating valuable exchanges among its users. [40] Investigated age differences and similarities in the usage of OSN website MySpace, where findings showed teenagers 
using music and video on their profile pages more than older individuals, with teenage girls receiving more comments on their profile pages than any other participating age group. It has also been cited that non-technical adoption factors are fundamental when encouraging older adults and their interaction behaviors [41] E-government is also employing technology and a study by [42] on senior citizens in terms of digital divide and e-government technology use suggested that concerns regarding service complexity, data security, and costs were deterrents of e-government service use. Digital divides are evident with technology, but [43] adopted a diverse perspective and suggested that a social capital divide emerges when using OSNs such as, MySpace. Comparatively, [44] found that participants were not interested in computer usage, especially when compared with other pastimes and activities that they were participating in.

\section{Theoretical Foundations}

To examine OSN adoption, use and diffusion, a theoretical conceptual model, the Model of Older Online Social Networking (MOSN) was formed. For this, the foundations were drawn from Technology Acceptance Model (TAM) [45], Diffusion of Innovations Theory (DoI) [46], Model of Adoption of Technology in Households (MATH) [47], Theory of Planned Behavior (TPB) [48], Theory of Reasoned Action (TRA) and Unified Theory of Acceptance and Use of Technology (UTAUT) [49]. These models were selected as they allow perspectives required to conduct such a study to be provided. For instance, attitudes, influences from friends and family, or other external parties such as, internet service providers, whether the new technologies or innovation, which Facebook is viewed as, is better than preceding technologies such as, e-mail or text messages and how individuals overcome encountered challenges when applying and using the new technologies.

\section{Research Approach}

Consideration of available resources such as time, logistics, manpower and an increased probability of obtaining a substantial sample size led to data collection in the form of an online survey questionnaire. Guided by [59] who suggested principles for questionnaire, this study's questionnaire comprised of three sections: (1) demographics (2) Internet Usage (3) OSN usage, totaling 39 items. For path analysis, the adapted construct measures utilized 5-point Likert scales (1:disagree > 5:agree) in order to procure data to test influences of the nine MOSN constructs on the dependent variable OSN usage. To gather a substantial number of participants, snowball sampling was pursued that involved daily and routine distribution (blog posting) of an introduction e-letter and survey-link on Surveymonkey.com requesting the co-operation of all ages (18+), including OSN non-users. The survey was conducted for 2 months (March 24th 2012 - May 24th 2012). The principal researcher initially began with 35 self-selected OSN accounts (Facebook, Twitter, LinkedIn \& MySpace) belonging to members residing in the sampling frame. This eventually led to 271 responses of which 19 responses were incomplete; thereby resulting in a final total of 252 responses.

Within this data set $50.4 \%$ were males and $49.6 \%$ female. Age ranges included; $18-30$

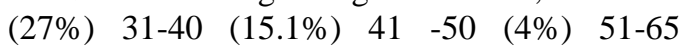
(27.4\%) $66-80(21.8 \%) .42 .8 \%$ of participants held undergraduate and/or postgraduate university degrees. The majority of participants were of white British origin $(71 \%)$ with the remaining $29 \%$ being Asian/British, mixed background or of another white background. Of the 252 participants (including 20 non-internet users) 142 were OSN users and 110 non-OSN users. 128 participants were of age ranges 18-50 years (forming the younger data set), 124 were 51 years and above (forming the older data set).

The sampling frame comprised residents from UK's London, Southeast and east of England. These areas were specifically selected due to their current economic contributions to economic growth in the UK. The south east of England is the second largest economic contributor among regions of England and UK countries and is responsible for nearly $15 \%$ of the UKs Gross Value Added (GVA) [60]. The East of England has the highest employment rate of any English region or country of the UK. Gross household income per head in Hertfordshire is the fourth highest in England [61]. London is by far the largest contributor to the economy within the English regions and countries of the UK. It makes its greatest contribution from financial and insurance activities [62].

\subsection{Pretest}

Pretesting is generally agreed to be an indispensable stage in development of survey questionnaires [65]. [66] found that on average the expert panel pretest method was most productive in the number of problems identified within a survey instrument and was also pursued by this study. The expert panel consisted of 20 diverse experts: 3 academic researchers, 3 researchers from industry, 3 
industry professionals, 3 medical professionals and 8 academic graduates. Each expert was asked to complete the online questionnaire and provide feedback based on a set of criteria (misinterpretation, intrusiveness, clarity and appropriateness of answer format). The pretest resulted in rewording of nine survey items to remove misinterpretation and improve clarity.

\section{Data Analysis and Findings}

Recognizing the potentials of OSN for internet use, which in turn could lead to economic growth, governments such as, the UK has begun to make investments (£100,000) [67]. Using the theoretical framework findings and analysis were acquired that provided demographic patterns in terms of adopters and non-adopters. By doing so, an extension to previous broadband studies such as, [68] that examined broadband adopters and non-adopters was possible.

A common pattern in terms of technology adoption is the gender bias [69];[70]. Tis study also attempted to determine whether the proportion of respondents adopting OSN is associated with gender (see Table 1). The Chisquare test confirmed $(\chi 2(1, N=252)=7.03, p$ $=0.008)$ this assumption. Table 1 illustrates that there are fewer female adopters, but in the nonadoption data, there were more females.

Table 1. Proportion of Adopters and Gender

\begin{tabular}{|l|cc|cr|}
\hline Gender & \multicolumn{2}{|c|}{ Adopter } & \multicolumn{2}{|c|}{ Non-Adopter } \\
\hline Male & 82 & $(65 \%)$ & 45 & $(35 \%)$ \\
Female & 60 & $(48 \%)$ & 65 & $(52 \%)$ \\
\hline
\end{tabular}

The frequency of Internet use and OSN adoption was also investigated (see OSN are reliant on the ICT infrastructure, namely broadband that this study made an assumption of. The ICT experience is usually associated with new ICT adoption as well [74] We considered Internet usage history as a proxy variable for experience (Table 3), and expected some level of association between usage history and adopter status.

Table 2). It was anticipated that Internet use frequency increases with OSN usage that the Chi-square test also confirmed $(\chi 2(2, \mathrm{~N}=232)$ $=51.85, \mathrm{p}<0.0001)$. While the Chi-square test only analyzes the association between variables, a literature review also revealed that Internet use levels and OSN-related activities are linked, with addiction particularly evident in younger age groups [71]; [72]; [73]. Indeed, in the 18-30 years old adopter group, $58 \%$ spent more than 2 hours on the Internet. This category steadily decreased to $42 \%, 32 \%, 13 \%, 12 \%$ and $7 \%$ in the $31-40,41-50,51-60,61-70,71-80$ age groups, respectively. This suggests that a divide in terms of OSN use and age-groups does exist.

OSN are reliant on the ICT infrastructure, namely broadband that this study made an assumption of. The ICT experience is usually associated with new ICT adoption as well [74] We considered Internet usage history as a proxy variable for experience (Table 3), and expected some level of association between usage history and adopter status.

Table 2. Internet Use Frequency

\begin{tabular}{|l|rr|rr|}
\hline \multicolumn{1}{|c|}{$\begin{array}{c}\text { Internet Use } \\
\text { Frequency }\end{array}$} & \multicolumn{2}{|c|}{ Adopter } & \multicolumn{2}{|c|}{$\begin{array}{c}\text { Non } \\
\text { Adopter }\end{array}$} \\
\hline $\begin{array}{l}\text { No Internet use } \\
\text { Once a month }\end{array}$ & 0 & $(0 \%)$ & 20 & $(100 \%)$ \\
$\begin{array}{l}\text { Once a week } \\
\text { Daily, more } \\
\text { than 2 hrs }\end{array}$ & 9 & $(21 \%)$ & 34 & $(79 \%)$ \\
$\begin{array}{l}\text { Daily, less than } \\
2 \text { hrs }\end{array}$ & 65 & $(88 \%)$ & 9 & $(12 \%)$ \\
\hline
\end{tabular}

The Chi-square test accordingly rejected the null hypothesis, but the results were statistically significant $(\chi 2(5, \mathrm{~N}=233)=12.35, \mathrm{p}=0.03)$.

Table 3. Internet Usage History

\begin{tabular}{|l|rr|rr|}
\hline $\begin{array}{c}\text { Internet } \\
\text { Usage } \\
\text { History }\end{array}$ & \multicolumn{2}{|c|}{ Adopter } & \multicolumn{2}{c|}{$\begin{array}{c}\text { Non } \\
\text { Adopter }\end{array}$} \\
\hline Non-user & 0 & $(0 \%)$ & 19 & $(100 \%)$ \\
Less than 1 yr & 7 & $(78 \%)$ & 2 & $(22 \%)$ \\
$1-2$ yrs & 17 & $(77 \%)$ & 5 & $(23 \%)$ \\
$2-4$ yrs & 18 & $(47 \%)$ & 20 & $(53 \%)$ \\
$4-6$ yrs & 40 & $(54 \%)$ & 34 & $(46 \%)$ \\
6-8 yrs & 25 & $(61 \%)$ & 16 & $(39 \%)$ \\
more than 8 & 37 & $(76 \%)$ & 12 & $(24 \%)$ \\
yrs & \multicolumn{3}{|c}{} \\
\hline
\end{tabular}

Bandwidth may be an issue for dialup or ISDN users, particularly in case of graphics-heavy applications (e.g. online photo albums). However, with the current relatively high bandwidth levels available to the majority of our respondents (67\% had above $20 \mathrm{Mbps}$ ), we did not expect bandwidth levels to be strongly associated with the adoption rates (see Table 4). The Chi-square test confirms that bandwidth levels are not associated with adoptions levels $(\chi 2(4, \mathrm{~N}=147)=3.51, \mathrm{p}=0.47)$. Table 4 reveals a large percentage $(47 \%)$ of adopters 
not being aware of the provided speeds; thus supporting the statistical inferences.

Previous research studies have also considered education levels for ICT, namely broadband, that is the platform providing OSN [75]. We also considered different education levels and types.

Table 4. Internet Connection Bandwidth

\begin{tabular}{|l|rr|rr|}
\hline $\begin{array}{c}\text { Internet } \\
\text { Bandwidth }\end{array}$ & \multicolumn{2}{|c|}{ Adopter } & \multicolumn{2}{c|}{$\begin{array}{c}\text { Non } \\
\text { Adopters }\end{array}$} \\
\hline Non-user & 0 & $(0 \%)$ & 20 & $(100 \%)$ \\
4-6 Mbps & 2 & $(67 \%)$ & 1 & $(33 \%)$ \\
5-9 Mbps & 6 & $(100 \%)$ & 0 & $(0 \%)$ \\
10-14 Mbps & 5 & $(71 \%)$ & 2 & $(29 \%)$ \\
Up to 20 & & & & \\
Mbps & 22 & $(67 \%)$ & 11 & $(33 \%)$ \\
Above 20 & & & & \\
Mbps & 62 & $(63 \%)$ & 36 & $(37 \%)$ \\
Do not know & 47 & $(55 \%)$ & 38 & $(45 \%)$ \\
\hline
\end{tabular}

For this data on degree and vocational types of education qualifications were sought. Also included were school level qualifications (GCSE and A level) data (Table 5). The Chisquare test rejected the null hypothesis $(\chi 2(2, \mathrm{~N}$ $=252)=6.21, \mathrm{p}=0.045)$ and suggested $\mathrm{a}$ relationship between adoption and education levels, although the $\mathrm{p}$ value is very close to the 0.05 limit. Table 5 shows that higher degree levels individuals are the larger numbers of adopters, whilst the vocational level individuals ranked higher in the non-adopters categories.

Table 5. Education Level and Type

\begin{tabular}{|l|cc|cc|}
\hline $\begin{array}{c}\text { Education } \\
\text { Type }\end{array}$ & \multicolumn{2}{|c|}{ Adopter } & \multicolumn{2}{c|}{$\begin{array}{c}\text { Non } \\
\text { Adopter }\end{array}$} \\
\hline Degree & 70 & $(65 \%)$ & 38 & $(35 \%)$ \\
School & 36 & $(54 \%)$ & 31 & $(46 \%)$ \\
Vocational & 36 & $(47 \%)$ & 41 & $(53 \%)$ \\
\hline
\end{tabular}

Age is also considered a typical factor when considering adoption and use [76]. It is usually expected that younger age-groups generally adopt OSNs more readily than older ones, which our analysis also revealed. From the data in Table 6, the Chi-square test results revealed a significant $\mathrm{p}$ and $\chi^{2}(5, \mathrm{~N}=252)=93.98, \mathrm{p}<$ 0.0001 that showed that younger users adopted OSN (63) more than older ones users (from 50 years, 36). .

Table 6. Age and OSN Adoption

\begin{tabular}{|c|cc|rr|}
\hline Age & \multicolumn{2}{|c|}{ Adopter } & \multicolumn{2}{|c|}{ Non Adopter } \\
\hline $18-30$ & 63 & $(93 \%)$ & 5 & $(7 \%)$ \\
$31-40$ & 30 & $(79 \%)$ & 8 & $(21 \%)$ \\
$41-50$ & 13 & $(59 \%)$ & 9 & $(41 \%)$ \\
$51-60$ & 25 & $(46 \%)$ & 29 & $(54 \%)$ \\
\hline
\end{tabular}

\begin{tabular}{|l|ll|ll|}
$61-70$ & 8 & $(19 \%)$ & 35 & $(81 \%)$ \\
\hline $71-80$ & 3 & $(11 \%)$ & 24
\end{tabular}

\begin{tabular}{l|ll|ll}
$71-80$ & 3 & $(11 \%)$ & 24 & $(89 \%)$ \\
\hline
\end{tabular}

We are aware that our respondent numbers are not evenly spread along the age groups; hence the actual number of respondents and the percentages of adopters and non-adopters are illustrated in Figure 1. Without any statistical analysis, it can be noted that in the younger age groups (18-30) adoption is overwhelming at an adoption rate of $93 \%$. The USA has also indicated similar results where the 18-30 age groups in 2010 also revealed a 93\% ubiquitous use [77] However, the adoption rate steadily declines. From previous research on broadband, which this research study assumes is a platform required to provide Facebook, the silver surfer age group have revealed that no interest, no relevance to current lifestyle [78] deters them from adopting the internet and broadband. This led us to examine the next age range of 31-50 ages, which has been exposed to various levels of ICT use and adoption due to government initiatives such as, free computer use in libraries [79]; [80]. Therefore it is presumed that particularly the 31-50 range should not suffer from the lack of related ICT skills - in fact, all respondents in the above mentioned age group (adopters and non-adopters alike), use some level of ICT in their daily lives (desktop computers, tablets or/and smartphones) and have Internet access.

Figure 1, Percentage of adopters and nonadopters in different age groups

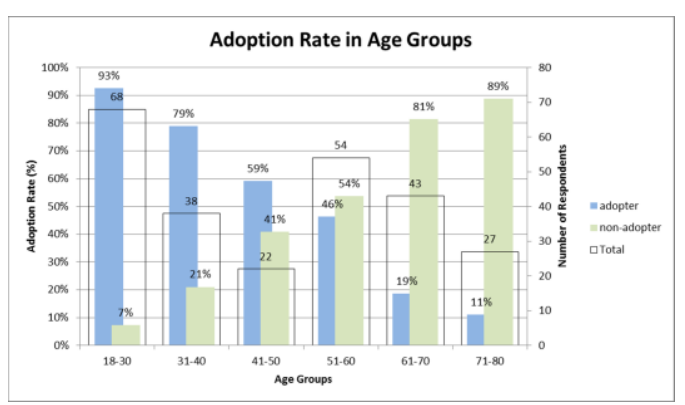

Thus Figure 1 prompts further analysis regarding the lower adoption rates in the 31-50 age groups.

To confirm that our findings of the UK are aligned with previous UK research data and to prevent a bias, comparisons were made between this research study and the regulatory body's data acquired from Ofcom Adult Media Use and Attitudes Report [81].

The OFCOM report provides a similar measure by seeking respondents questions regarding their own social networking profiles. Percentages are displayed for the adopters within the given age group for 2007, 2009, 
2010 and 2011 (base numbers: total of 1723 in 2007, 1282 in 2009, 1489 in 2010, 1369 in 2011).

Figure 2 displays a similar finding to our results, although different age groups are utilized. However, the adoption rate in the midage group proffers a similar value. Additionally, the longitudinal element of the chart also shows that the growth rate slows down as age groups near their saturation point. Whether this saturation point - particularly for a specific OSN like Facebook - is closer to $100 \%$ or at a lower value in a given age group, is still open for debate.

Figure 2, Percentage of adopters over years in different age groups

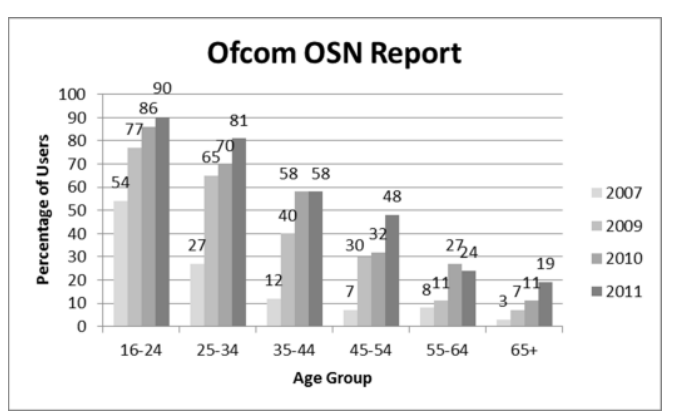

To gain further insights into adoption and use issues since OSNs are still developing in society, an identification of the types of OSNs being used by the various age groups was conducted (Figure 3 ). Due to the relatively low number of respondents, particularly in the 'silver surfer' age group, statistical analysis is not recommended. However, viewing the OSNs used in various age groups, LinkedIn use is increasing (as a professional HR / work related tool) from $10 \%$ to $57 \%$ across the $18-30$ to 51 60 age groups. This may reflect on the different needs and goals of diverse age groups; hence questioning the growth opportunities of Facebook. The current problems of Facebook (e.g. how to increase the user base further in UK) are clearly demonstrated by having a similar adoption rate within the 18-50 age range. Finding new adopters will likely to require some additional functionality to boost perceived usefulness.

Figure 3. OSN Usage by Age Groups

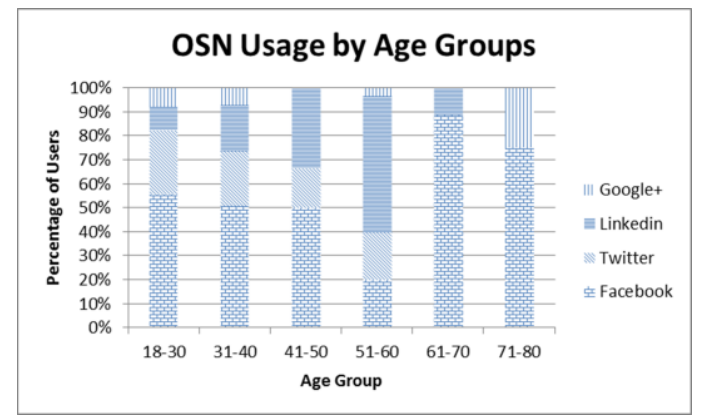

\section{Discussion}

Summarizing our demographic results from the entire dataset, it has been found that age, gender, education, Internet usage history and usage frequencies are all associated with adoption rates. A possible answer could be due to the levels of readily available bandwidths. However, Internet speed was not associated with adoption and is a factor that needs to be examined in greater detail. This aligns with control construct of facilitating control resources issue that has been identified as important in previous studies [82], which is why it is suggested that this requires greater detail. Statistical analysis was also conducted of the theoretical factors that showed that the demographic factors, age and education are significant demographic predictors of OSN use, which again shows that this issue can also be examined as a digital divide perspective, which the entire dataset also confirms.

An interesting issue emerged regarding the OSN adoption percentage rates and OSN type usage in different age groups. Most studies concentrate either on young age groups or silver surfers. Our demographics data shows the need to analyze the middle age group as well, understand their needs and requirements for social networks. This is particularly strong when considering and contrasting the use of LinkedIn to Facebook. It appears that LinkedIn is more or at least appealing to middle age groups that we attributed to possibly professional career reasons. At the same time, using BranchOut, a Facebook app with 25 million users, Facebook adopters may soon achieve similar professional referral and connections as with LinkedIn. Further research is needed to understand how different functionalities are catering for needs of different age groups and how adopters are differentiating OSNs. The assumption that a saturation point (75\% of adoption) would be achieved similarly by all age groups in one OSN may be premature at this point.

By conducting this study, the implications for academia is that theoretical models used for broadband, the platform providing OSN along with newer factors could proffer extensions to existing internet adoption and use understanding, something amiss until this point. For industry this research provides a better understanding of issues related with demographics that marketing and Internet Service Providers could find useful in 
promoting products and services in the future. For policymakers this research provides an understanding of demographics that are important to emphasize when considering increasing adoption and users. As mentioned governments such as, UK are using funds to advertise on Facebook. This study identifies groups that require more attention than others; hence providing policymakers with unbiased important and interesting information.

\section{Conclusions}

The aim of this research was to identify, explain and understand the adoption, use and diffusion of OSNs within UK's population. Results from an overall 252 participant's revealed that age, gender, education, Internet usage history and usage frequencies are all associated with adoption rates. Also found is that Internet speed was not associated with adoption and is a factor that needs to be examined in greater detail. Previous research of the theoretical factors also revealed age and education are significant demographic predictors of OSN use, which again shows that this issue can also be examined as a digital divide perspective. This leads to the conclusion that provision and penetrations of novel and innovative technologies may require examining the aforementioned factors but in terms of age and education and not to take issues such as, internet speed and adopters for granted when diffusing novel technologies within the population.

Prior to commencing this study, emerging limitations were not known; however, completion of this study identified certain limitations. First, the findings of this research are representative of individuals residing in an affluent area of UK. It is felt that completion of such a study at a national or global scale within diverse societies could lead to different outcomes. Also, a convenience sampling method was employed which may limit the extent to which the results can be extrapolated to the selected groups of interest in the UK. To overcome this limitation, it is suggested that a larger sample population size and employing a multi-stage random sampling methodology could increase the value and implications of these research findings.

\section{References}

[1] Cho.S, Jae-Ho.B and Sung.M. (2003) "Impact of the high-speed Internet on user behaviors: case study in Korea", Internet Research, Vol. 13 Issue 1, pp.49 $-60$
[2] Hellman.B and Haythornthwaite.C (2002) The Internet in everyday life Wiley-Blackwell publishing

[3] Oh.S, Ahn.S. and Kim.B (2003). "Adoption of broadband Internet in Korea: the role of experience in building attitude" Journal of Information

Technology, 18 (4), p 267-280.

[4] Ritchie, B. and Brindley, C. (2005), 'ICT Adoption by SMEs: Implications for Relationships and Management,' New Technology, Work and $\begin{array}{lllll}\text { Employment, } & 20 & \text { (3), } & \text { p } & \text { 205-217. }\end{array}$ [5] OECD (2005) Good practice paper on ICTs for economic growth and poverty reduction Available at: http://www.oecd.org/dataoecd/2/46/35284979.pdf

[6] Stanoevska-Slabeva.K (2002) "Toward a Community-Oriented Design of Internet Platforms" International Journal of Electronic Commerce Vol. 6, No. 3, p. 71-95.

[7] [8] Constantinides.E and Fountain.S (2008), "Web 2.0: Conceptual Foundations and Marketing Issues" Journal of Direct, Data and Digital Marketing Practice Web 2.0 definition vol. 9, issue 3 p 232

[9] Wellman, B (1996) For a social network analysis of computer networks: a sociological perspective on collaborative work and virtual community. Proceedings of the SIGCPR/SIGMIS, Denver, CO p $1-11$

[10] Cheung.C.M.K, Chiu.P \& Lee.M.K.O (2011) Online social networks : Why do students use Facebook? Computers in human behavior Vol $27 \mathrm{p}$ 1337-1343

[11] Facebook (2012) "Fact Sheet" Available at: http://newsroom.fb.com/content/default.aspx?NewsA reaId $=22$

[12] Qualman.E (2011) 100 million on linkedininfographic by country Available at: http://www.socialnomics.net/2011/03/28/linkedinhits-100-million-breakdown-by-country-graphic/

[13] Digital Surgeons (2010) Facebook Vs Twitter Statistics Available at: www.digitalsurgeons.com/facebook-vs-twitterinfographicl

[14] NielsenWire (2009) "Led by Facebook, Twitter, Global Time Spent on Social Media Sites up $82 \% \quad$ Year over Year" Available at:

http://blog.nielsen.com/nielsenwire/global/led- byfacebook-twitter-global-time-spent-on- social-mediasites-up-82-year-over-year/

[15] Gadsby.S (2010) "Facebook, Industry News, Social Network Marketing : Active users in Europe" Available at: http://www.clickymedia.co.uk/2010/04/ukfacebook-user-statistics-april-2010/

[16] Schaefer.C (2008) "Motivations and Usage 
Patterns on Social Network Sites" ECIS Proceedings. Paper 143

[17] O'Murchu, Breslin.J.G \& Decker.S (2004) Online social business networking communities Digital Enterprise Research Institute (DERI)

[18] Chang.A \& Kannan.P.K (2008) Leveraging Web 2.0 in government IBM center for the business of government (E-government/technology series).

[19] Lyons.G (2010) "Social Media Demographics , Facebooks for girls"

Available at : http://connect.icrossing.co.uk/socialmedia- demographics-facebooks-girls_1562

[20] [21] Palfrey.J \& Gasser.U (2008) Born Digital;Understanding the first generation of digital natives Basic Books

[22] NetLingo (2010) Silver Surfers : Definition Available from: http://www.netlingo.com/word/silver-surfer.php

[23] [44] Selwyn.M (2004) The information aged: A qualitative study of older adults use of information and communication technology Journal of ageing study Vol 18 p 369-384

[24] UN DESA (2007) (United Nations Department of Economic and Social Affairs) Population Division World Population Report 2007

[25][26] Jeavans.C (2004) Welcome to the ageing future BBC News Available at: http://news.bbc.co.uk/1/hi/uk/4012797.stm

[27] Mitzer.T, Boron.J, Fausset.C, Adams.A, Charness.N, Czaja, Diikstra, Fisk.A, Rogers.W \& Sharit.J (2010) Older adults talk technology: Technology usage and attitudes Computers in Human Behavior Vol 26 (2010) pp 1710-1721

[28] Muscanell.N.L \& Guadagno.R.E (2012) Make new friends or keep the old: Gender and personality differences in social networking use Computers in Human Behavior Vol 28 p 107 - 112

[29] Peng.G \& Mu.J (2011) Technology adoption in online social networks Journal of product innovation management Vol 28 S1 p 133-145

[30] Niehaves.B and Plattfaut.R (2011) "The MATH of Internet Adoption: Comparing Different AgeGroups". Wirtschaftinformatik Proceedings 2011. Paper 23.

[31] [33] [69] [73] Maier.C, Laumer.S \& Eckhardt.A (2011) Technology Adoption by Elderly People - An Empirical Analysis of Adopters and Non-Adopters of Social Networking Sites Proceedings of the 10th International Conference on Wirtschaftsinformatik 2011, pp. 901-911
[32] [47] [51][53][58] Venkatesh.V \& Brown.S (2001) A longitudinal investigation of PC in homes: adoption determinants and emerging challenges. MIS Quarterly Vol 25 No1 pp 71- 102

[34] Bauer.C, Korunovska.J \& Speikermann.S (2012) On the value of information - What Facebook users are willing pay ECIS 2012 Proceedings

[35] Norris, P. (2001) Digital Divide: Civic Engagement, Information Poverty and the Internet in Democratic Societies, Cambridge University Press, New York.

[36] [37] Warschauer, M. (2003). Technology and Social Inclusion: Rethinking the Digital Divide, Cambridge, Mass, the MIT Press.

[38] Pempek.T.A, Yermolayeva.Y.A \& Calvert.S.L (2009) College students social networking experiences on Facebook Journal of applied developmental psychology Vol 30 p $227-238$

[39] Schondienst.V \& Dang-Xuan.L (2012) '...A friend indeed?' - An empirical analysis of interactions on Facebook ECIS 2012 Proceedings

[40] Pfeil.U , Arjan.R and Zaphiris.P (2009) "Age differences in online social networking - A study of user profiles and the social capital divide among teenagers and older users in MySpace" Computers in human behavior Vol 25 pp $643-65$

[41] Choudrie.J, Grey.S \& and Tsitsianis.N (2008) "Evaluating the Digital Divide: The Silver Surfer's Perspective" GlobDev 2008. Paper 1.

[42] Niehaves.B, Bergener.P, Rackers.M \& Becker.J (2008) You Got E-Government?' A Quantitative Analysis of Social In- and Exclusiveness of Electronic Public Service Delivery ECIS 2008 Proceedings Paper 32

[43] Adams.N, Stubbs.D \& Woods.V (2005) Pscychological barriers to internet usage among adults in the UK Medical informatics and the internet in medicine Vol 30 p 3-17

[45] Davis.F, (1989), "Perceived Usefulness, Perceived Ease Of Use And User Acceptance Of Information Technology", MIS Quarterly, Vol 13 pp $319-340$

[46] [52] Rogers.E.M, (2003) Diffusion of Innovations. Free Press, New York

[48] Ajzen.I, (1991). "The theory of planned behavior" Organizational Behavior and Human Decision Processes, 50, $\mathrm{p}$ 179-211

[49] Venkatesh.V, Morris.M.G, Davis.G.B \& Davis.F.D (2003) User acceptance of information technology: Toward a unified view Vol 27 No.3 pp 425-478

[50] [55] Eagly, A. H., \& Chaiken, S. (1993). The psychology of attitudes. Fort Worth: Harcourt Brace Jovanovich College Publishers. 
[54] [57] Macredie.R.D \& Mijinyawa.K (2011) A theory-grounded framework of Open Source Software adoption in SMEs European Journal of Information Systems Vol 20, pp 237-250

[56] Taylor, S \& Todd, P (1995a) Decomposition and crossover effects in the theory of planned behaviour: A study of consumer adoption intentions. International Journal of Research in Marketing Vol 12 (2) pp 137-155.

[59] Dillman.D.A (2007) Mail and internet surveys: A tailored design method Second Edition John Wiley \& Sons Inc.

[60] ONS (2012) Regional Profiles - Economy South-East (May 2012) Available at: http://www.ons.gov.uk/ons/rel/regionaltrends/region-and-country-profiles/economy---may2012/economy---south-east--may-2012.html

[61] ONS (2012) Regional profiles - Economy East of England (May 2012) Available at: http://www.ons.gov.uk/ons/rel/regionaltrends/region-and-country-profiles/economy---may2012/economy---east-of-england--may-2012.html

[62] ONS (2012) Regional Profile -Economy London (May 2012) Available at: http://www.ons.gov.uk/ons/rel/regionaltrends/region-and-country-profiles/economy---may2012/economy---london--may-2012.html

[63] Rossiter.J.R (2008) Content validity of measures of abstract constructs in management and organization research British Journal of Management Vol. 19 p 380-388

[64] Lawshe.C (1975) "A quantitative approach to content validity" Personnel Psychology, 28, pp 563575

[65] [66] Presser.S \& Blair.J (1994) Survey pretesting: Do different methods produce different results? Sociological Methodology Vol 24 pp 73104

[67] Jones, R-C. (2012). Facebook ads: $£ 100,000$ bill for government - good value?. Available at: http://www.bbc.co.uk/news/technology-19396785.

Viewed: August 28, 2012.

[68] Dwivedi Y.K. and Irani, Z. (2009), Understanding the Adopters and Non-adopters of Broadband, Communications of the ACM, 52(1), 122-125.[DOI:

http://dx.doi.org/10.1145/1435417.1435445]

[69] Choudrie, J. and Dwivedi, Y. K. (2006). A comparative study to examine the socio-economic characteristics of broadband adopters and nonadopters. Electronic Government, an International Journal. 3, 3 .

[70] [75] [78] Choudrie, J., Grey, S., Haslam, C. and Tsitsianis, N. (2011) Identifying adopters and non- adopters of Broadband amongst silver surfers: using BHPS. Electronic Government: An International Journal, 8, (1): p.40-58.

[71] Kanwal.N \& Anand.A.P (2003). Internet Addiction in Students: A Cause of Concern. CyberPsychology \& Behavior. 6(6): p.653-656

[72] Karaiskos, D., Tzavellas, E., Balta, G., \& Paparrigopoulos, T. (2010). Social network addiction : a new clinical disorder? European Psychiatry, 25, p. $855-855$

[73] Block, J. (2008). Issues for DSM-V: Internet Addiction. American Journal of Psychiatry, 165 (3), p.306-307

[74] [80] Choudrie, J. and Dwivedi, Y. K. (2006). A comparative study to examine the socio-economic characteristics of broadband adopters and nonadopters. Electronic Government, an International Journal. 3, 3 .

[76] [82] Ooi, K-B, Sima, J.J, Yew, K.T., Lin,,B. (2007). Exploring factors influencing consumers' behavioral intention to adopt broadband in Malaysia. Computers in Human Behavior. 27, (3)

[77] Lenhart, A., Purcell, K, Smith, A and Zickuhr, K. (2010). Social Media \& Mobile Internet Use among teens and young adults. Available at: http://web.pewinternet.org/ /media/Files/Reports/20 10/PIP_Social_Media_and_Young_Adults_Report_F inal_with_toplines.pdf. Viewed: August 30, 2012.

[79] Choudrie, J, Brinkman, W-P., Pathania, R. (2007). Using diffusion theory to determine the digital divide in e-services: two UK local-area perspectives. EG 4(3): 345-359 (2007)

[81] OfCom (2012) Adults media use and attitudes Available at:http://stakeholders.ofcom.org.uk /binaries/research/media-literacy/media-useattitudes/adults-media-use-2012.pdf)

[Accessed:2012] 